\title{
THE EFFECT OF PHOSPHOROUS ON
}

\author{
MECHANICAL PROPERTIES OF ALLOY 718 \\ Wei-Di Cao and Richard L. Kennedy \\ Teledyne Allvac \\ 2020 Ashcraft Avenue \\ Monroe, NC 28110
}

\begin{abstract}
Phosphorous is generally regarded as detrimental in Ni-base alloys; consequently most specifications restrict $P$ to low levels $(<0.015 \%)$. The effect of $P$ on the tensile, rupture, and hot workability of alloy 718 was investigated on product produced from VIM + VAR heats.

Increasing $P$ content from the $0.004 \%-0.009 \%$ range, typical of most commercial product, to $0.022 \%$ increased rupture life by 2 to 2.5 times at $649^{\circ} \mathrm{C}$. Other properties were not appreciably changed. Decreases in $P$ content to levels as low as $0.0007 \%$ resulted in a severe loss of rupture life giving a total spread of more than one order of magnitude. Microstructural, Auger Electron Spectroscopic and SEM fractographic analyses were performed to explore the possible mechanism of the observed $P$ effect. It is suggested that grain boundary segregation of $\mathrm{P}$ and $\mathrm{P}$-dislocation interaction were responsible for the improvement in stress rupture properties. These effects were most pronounced in fine grained product and may, therefore, be helpful in resolving rupture/creep limitations in ultra-fine grained 718 .
\end{abstract}




\section{Introduction}

The effect of Phosphorous on the mechanical properties of nickel-base superalloys has not been studied or reported in great detail, but there is some controversy in the literature as reflected in a number of overview papers (1-4). Most investigators regard $P$ as a detrimental element which causes grain boundary embrittlement (2-4). Seah (5) concluded, from considerations of sublimation enthalpy, which provides a good guide to the atomic bond strength, that $P$ increases grain boundary embrittlement of nickel by reducing its energy of sublimation. Experimentally, Yemiscavich and Fox (6) have shown that $P$, together with $B, C$, and $S$ promotes high temperature $\left(760^{\circ} \mathrm{C}-980^{\circ} \mathrm{C}\right)$ cracking and hot tearing during Gleeble tests of cast Hastelloy $\mathrm{X}$. Cononico, Savage, Werner, and Goodman (7) reported similar results in Incoloy 800 . However, early work by Bieber and Decker (1) reported $P$, in small amounts, to be beneficial to malleability, particularly in the red short zone $\left(500^{\circ} \mathrm{C}-800^{\circ} \mathrm{C}\right)$ and suggested adding $P$ to improve hot working ductility. Unfortunately, they did not provide experimental evidence to support their conclusion. Recently Was and his co-workers (8-10) performed a systematic study on the effect of $P$ and other trace elements $(C$ and $B)$ on the microstructure, intergranular stress corrosion cracking, and creep resistance of $\mathrm{Ni}-\mathrm{Cr}-\mathrm{Fe}$ alloy 600 . It was revealed that the addition of $P$ to $\mathrm{Ni}-\mathrm{Cr}$-Fe alloy 600 improved the intergranular cracking resistance and creep resistance in Ar or high temperature water.

Recognizing the theoretical and practical importance of clarifying the role of $P$, a study was undertaken in an effort to optimize trace element levels in superalloys. In particular the effect of $P$ was evaluated on the microstructure and mechanical properties of alloy 718. This paper will report the findings in fine grained alloy 718 with $P$ levels as the sole variable.

\section{Experimental Procedure}

\section{Test Material}

The test alloys were vacuum induction melted (VIM) with a weight of $23 \mathrm{Kg}$ per heat and cast as $70 \mathrm{~mm}$ diameter electrodes. VIM electrodes were further refined by vacuum arc remelting (VAR) to $100 \mathrm{~mm}$ diameter ingots.

VIM/NAR ingots were homogenized for 16 hours at $1190^{\circ} \mathrm{C}$ to minimize microsegregation. After cutting sample coupons for rapid strain rate tensile tests in the as-cast state, the remaining material was rolled to $15 \mathrm{~mm}$ diameter bars within the temperature range of $1040^{\circ} \mathrm{C}$ to $920^{\circ} \mathrm{C}$.

The chemical compositions of test alloys determined on intermediate size bars $(60 \mathrm{~mm}$ diameter) are listed in Table I. It can be seen from this table that the P level is the only significant variable among the compositions and covers a wide range from a low of

\footnotetext{
Hastelloy is a trademark of Haynes International.

Incoloy is a trademark of the INCO family of companies.
} 
TABLE I. - CHEMICAL COMPOSITION OF TEST ALLOYS

\begin{tabular}{|c|c|c|c|c|c|c|c|c|c|c|c|c|}
\hline $\begin{array}{l}\text { HEAT } \\
\text { NO. }\end{array}$ & C & S & Mo & $\mathrm{Cr}$ & $\mathrm{Fe}$ & $\begin{array}{c}\mathrm{Nb} \\
\mathrm{t} \\
\mathrm{Ta}\end{array}$ & $\mathrm{Ti}$ & Al & $\mathrm{Si}$ & B & $\mathrm{N}$ & \\
\hline G577-1 & 0.032 & 0.0006 & 2.90 & 17.86 & 19.47 & 5.11 & 0.94 & 0.58 & 0.01 & 0.003 & 0.0021 & 0.1 \\
\hline G455-1 & 0.032 & 0.0004 & 2.86 & 17.84 & 19.37 & 5.08 & 0.94 & 0.63 & 0.05 & 0.004 & 0.0024 & 0.1 \\
\hline G498-1 & 0.035 & 0.0008 & 2.89 & 17.59 & 19.77 & 5.16 & 0.94 & 0.58 & 0.03 & 0.004 & 0.0035 & 0. \\
\hline G497-1 & 0.033 & 0.0009 & 2.89 & 17.65 & 19.65 & 5.09 & 0.93 & 0.57 & 0.02 & 0.004 & 0.0032 & 0. \\
\hline G500-1 & 0.035 & 0.0006 & 2.86 & 17.70 & 19.44 & 5.18 & 0.92 & 0.53 & 0.13 & 0.004 & 0.0041 & 0. \\
\hline G729-1 & 0.032 & 0.0006 & 2.84 & 18.04 & 19.35 & 5.03 & 0.93 & 0.58 & 0.01 & 0.003 & 0.0017 & 0. \\
\hline G672-2 & 0.035 & 0.0005 & 2.85 & 17.95 & 19.31 & 5.19 & 0.93 & 0.56 & 0.01 & 0.005 & 0.0012 & 0. \\
\hline G671-2 & 0.028 & 0.0004 & 2.86 & 17.78 & 19.32 & 5.16 & 0.93 & 0.59 & 0.01 & 0.004 & 0.0012 & 0. \\
\hline G728-2 & 0.033 & 0.0006 & 2.85 & 18.00 & 19.41 & 5.03 & 0.92 & 0.59 & 0.01 & 0.004 & 0.0018 & 0. \\
\hline
\end{tabular}


$0.0007 \%$ to a high of 0.0330 weight percent. Although not included in this report, more than one heat of certain critical compositions was made to confirm the observed trend.

\section{Heat Treatment}

Specimen blanks for tensile and stress rupture tests were cut from $15 \mathrm{~mm}$ diameter rolled bars and subjected to standard heat treatment as follows: solutioned for $1 \mathrm{hr}$ at $954^{\circ} \mathrm{C}$, air cooled and then aged for $8 \mathrm{hrs}$ at $718^{\circ} \mathrm{C}, \mathrm{FC}$ to $621^{\circ} \mathrm{C}$, held at $621^{\circ} \mathrm{C}$ for $8 \mathrm{hrs}$, air cooled.

\section{Mechanical Tests}

Rapid Strain Rate Tensile Test (RSRTT). To evaluate the effect of $P$ on hot workability, rapid strain rate tensile testing was performed on specimens cut from a mid-radius location of homogenized ingots at temperatures from $816^{\circ} \mathrm{C}$ to $1149^{\circ} \mathrm{C}$ and a tensile rate of approximately $5 \times 10^{-2} \mathrm{~S}^{-1}$. Three specimens were tested at each condition, and the average values were used to evaluate the $P$ effect.

Tensile and Stress Rupture Tests. Tensile tests were conducted at room temperature and $649^{\circ} \mathrm{C}$ in compliance with ASTM-E8, and stress rupture tests were performed in air at $649^{\circ} \mathrm{C}$ at constant initial applied stress levels of either $669 \mathrm{MPa}$ or $773 \mathrm{MPa}$. No attempt was made to determine the strain vs time dependence, and only the life time, total elongation, and reduction in area were measured after the specimens were broken. Three specimens were tested at each test condition.

Microstructure and Fractography. The microstructure of test alloys was examined by optical and Scanning Electron Microscopy (SEM) studies with the emphasis on characterizing their grain structure and phase morphology. A number of studies $(11,12)$ have demonstrated that $P$ segregates to grain boundaries in nickel-base alloys. Auger Electron Spectrometry (AES) was performed on selected alloys to confirm the grain boundary segregation of $P$ and its effect on the segregation of other elements. The notched AES specimens were cathodically hydrogen charged for $240 \mathrm{hrs}$ at room temperature in $1.8 \mathrm{NH}_{2} \mathrm{SO}_{4}+250 \mathrm{mg} / \mathrm{l} \mathrm{As}{ }_{2} \mathrm{O}_{3}$ solution at a current density of $50 \mathrm{~mA} / \mathrm{cm}^{2}$. The AES samples were loaded in the vacuum chamber of PHI 660 Scanning Auger Microprobe and fractured by impact loading at a vacuum better than $1.33 \times 10^{-7} \mathrm{pa}\left(1 \times 10^{-9}\right.$ Torr). The acceleration voltage and current of the primary electron beam were $10 \mathrm{Kv}$ and $19 \mathrm{nA}$, respectively. The details of AES measurement can be found in Ref. 13.

The fracture surface of particular stress rupture test specimens was examined by SEM. Special attention was paid to identifying the fracture mode at different test conditions in different alloys and clarifying the effect of $\mathrm{P}$ on the fracture process of alloy 718 .

\section{Experimental Results}

Rapid Strain Rate Tensile Test (RSRTT). Results from the rapid strain rate testing of ingot are shown in Figures 1-3. Although there was considerable scatter, typical of 


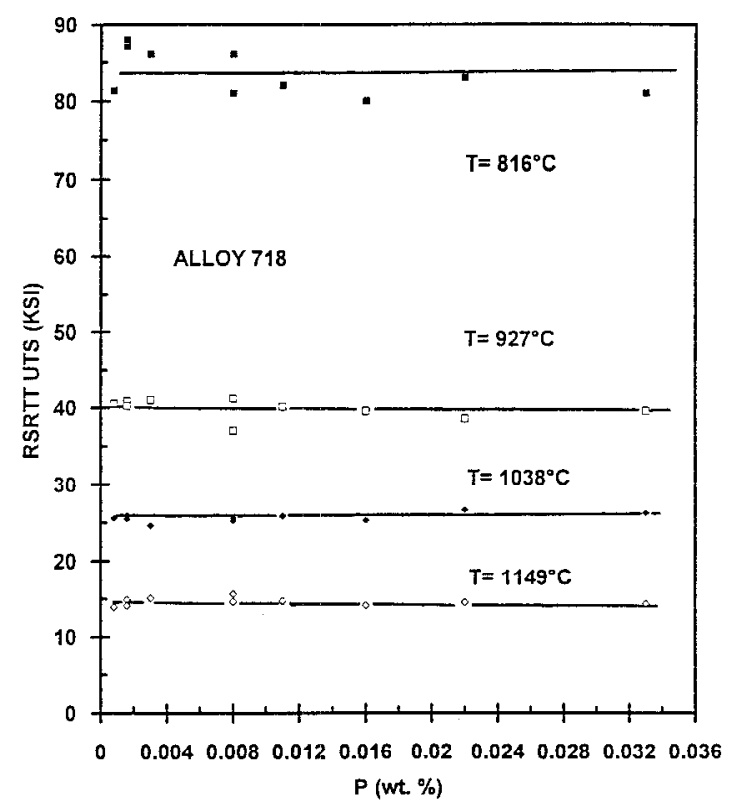

Fig. 1. Effect of P Level on RSRTT Tensile of Alloy 718.
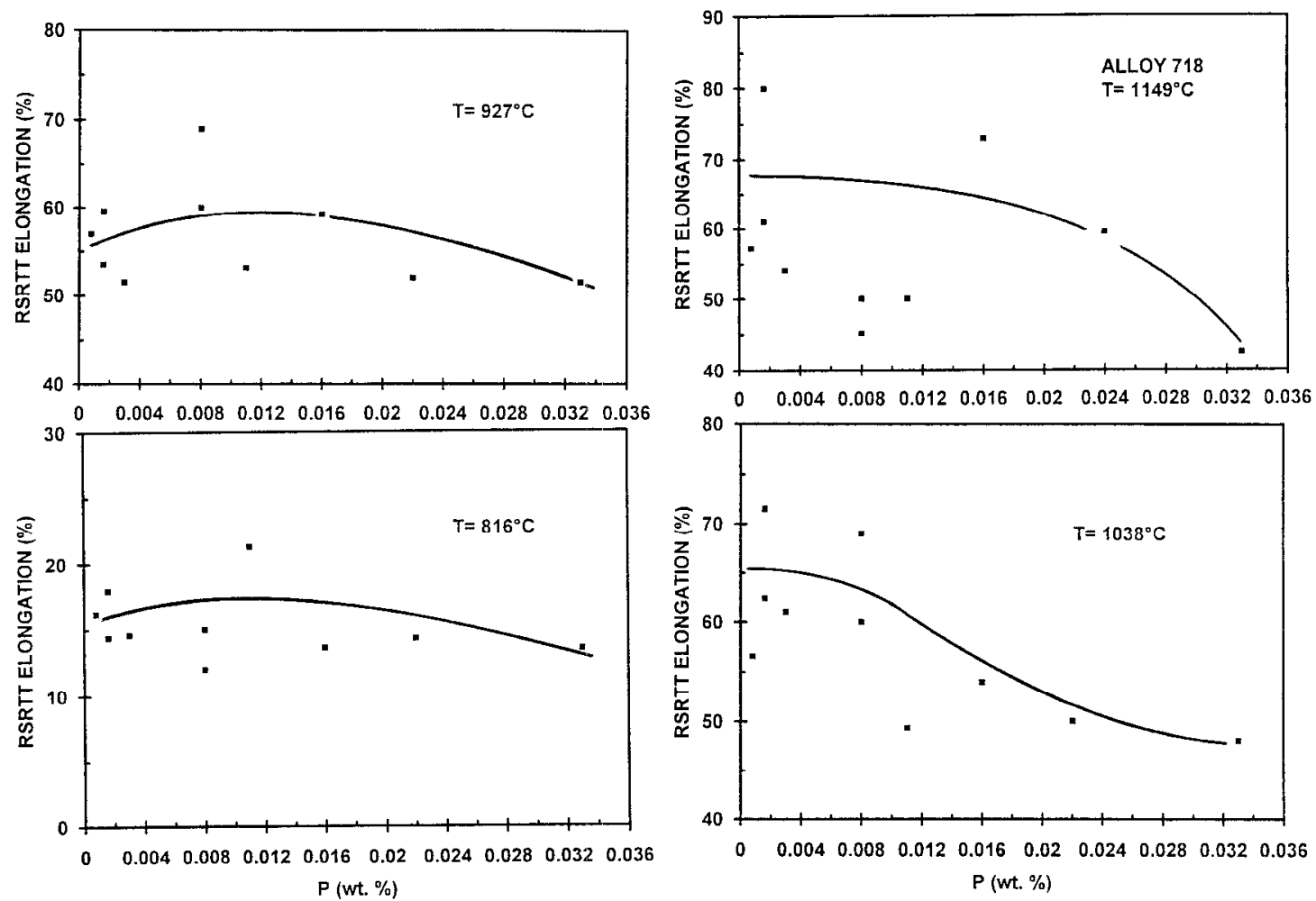

Fig. 2. RSRTT Elongation as a Function of $P$ Level in Alloy 718. 

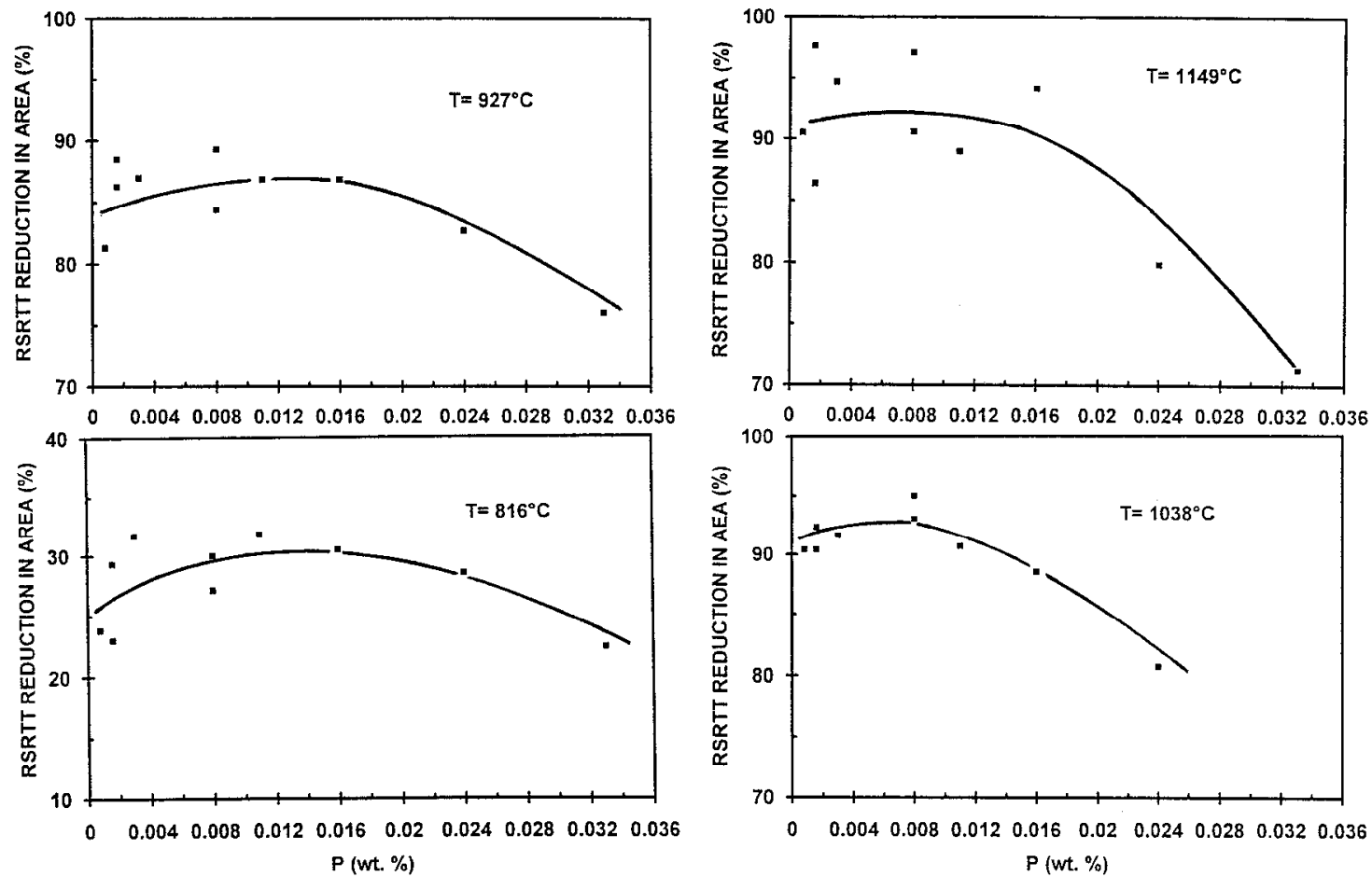

Fig. 3. Effect of P Level on RSRTT Reduction in Area of Alloy 718.
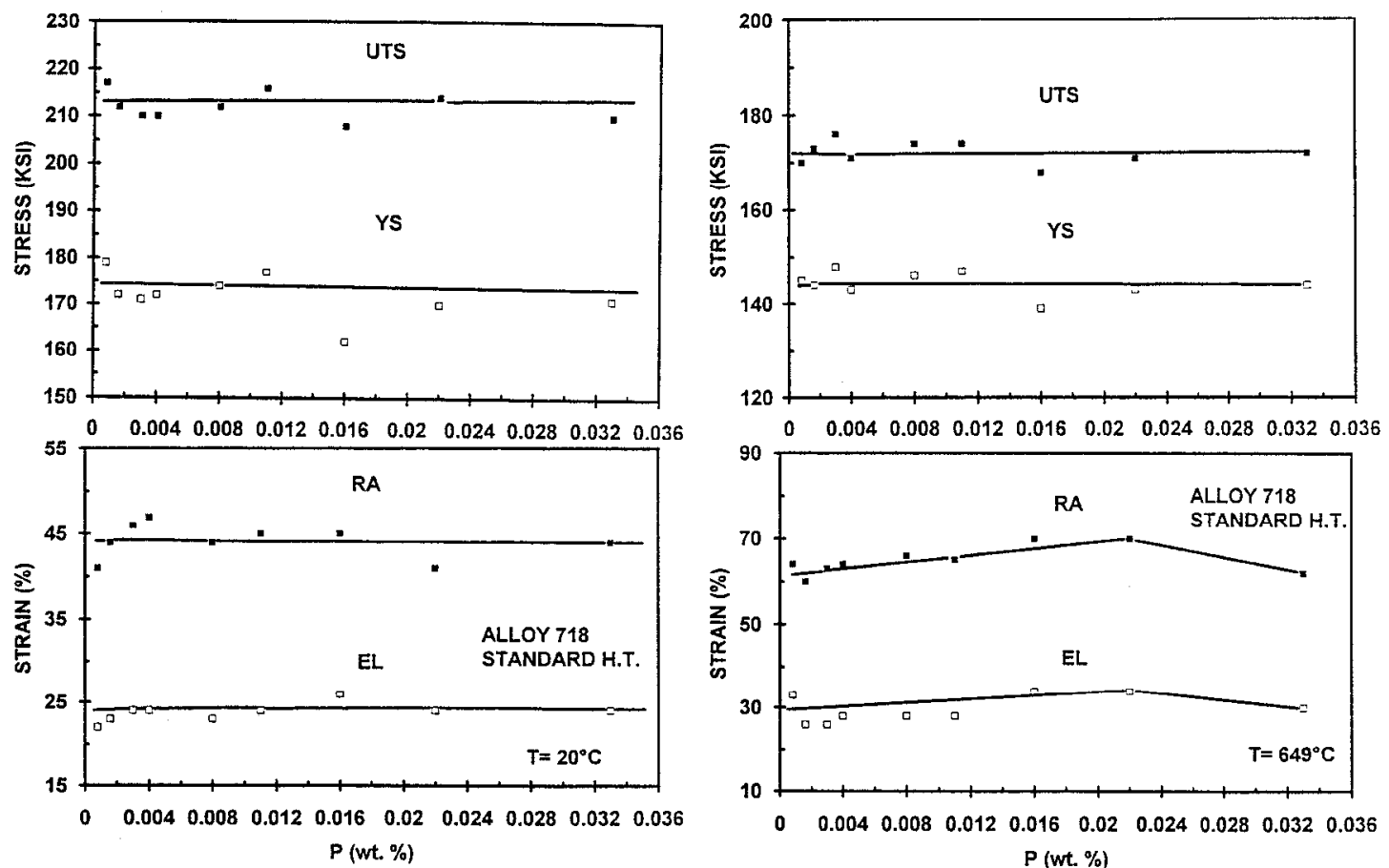

Fig. 4. Effect of P Content on Room Temperature Tensile Properties of Alloy 718, Standard Heat Treatment.

Fig. 5. Effect of $P$ Content on the Elevated Temperature Tensile Properties of Alloy 718, Standard Heat Treatment. 
coarse grained cast material, it can be seen that $P$ level had no noticeable effect on strength. Contrary to the conclusions of Bieber and Decker (1), there was very little or no effect of $P$ content, up to a level of about $0.020 \%$, on hot ductility at any test temperature. Above this level, ductility dropped slightly with increasing P content at all test temperatures. The decrease was greatest at the highest temperature, however, none of the ductility related effects were very significant. No difficulty was encountered in rolling any of the test alloys, indicating reasonable hot workability was maintained even in the high $P$ content alloys.

Tensile Properties. The $P$ level had no effect on strength or ductility of alloy 718 wrought bar at room temperature (Fig. 4). However, an increased $P$ level slightly improved the tensile ductility at elevated temperature $\left(649^{\circ} \mathrm{C}\right)$ with the strength being unchanged, (Fig. 5).

Stress Rupture (SR) Properties. The most striking effect of $P$ in fine-grained 718 bar was the change in stress rupture properties. As shown in Figures 6 and 7, the stress rupture life time significantly increased with an increased $P$ level and reached a maximum at about $0.02 \% \mathrm{P}$ for both applied stresses at $649^{\circ} \mathrm{C}$. The percentage increase was as high as about $250 \%$ in comparison to conventional 718 with a typical $P$ level from $0.004 \%$ to $0.009 \%$. An order of magnitude increase in rupture life was observed as $P$ content changed from $0.0007 \%$ to about $0.020 \%$ at both stress levels tested. P had no significant effect on stress rupture ductility, except for a consistent minimum observed at about $0.003 \%$, (Fig. 8 and 9 ).

Microstructure and Grain Boundary Chemistry. The microstructures of two representative test alloys in the as-heat treated state and after stress rupture testing are shown in Figure 10. It can be seen that the microstructures of low and high $\mathrm{P}$ alloys were essentially identical at the SEM level in both conditions. The amount of delta phase appears to have increased very slightly in both alloys after stress rupture testing, although no quantitative measurements were made. The grain sizes of all the test alloys were basically identical at 4-6 $\mu \mathrm{m}$ in diameter and no visible phosphide particles were found with the SEM-EDS. The fine-scale microstructure at the TEM level is currently being studied.

A limited AES study suggested increased $P$ segregation to grain boundaries in high $P$ alloys (Fig. 11). No other significant elemental differences were apparent in the grain boundaries of test alloys with different $P$ levels.

Fractography. The SEM fractographs of broken stress rupture specimens are shown in Figures 12 and 13 . In the alloy containing the lowest $P$ level $(0.0007 \%)$, the stress rupture failure at the lower stress (669 MPa) started at the surface of the specimen by intergranular cracking and ended with a transgranular dimple fracture (Fig. 12a to c). The fracture mode changed to completely intergranular separation at about $0.003 \% \mathrm{P}$, (Fig. 12d). As the $P$ level increased further, the intergranular fracture gradually diminished, and a completely ductile shear fracture mode was established at greater than $0.011 \% \mathrm{P}$, (Fig. $12 \mathrm{e} \& \mathrm{f})$. Fractures at the higher stress level $(773 \mathrm{MPa})$ occurred 


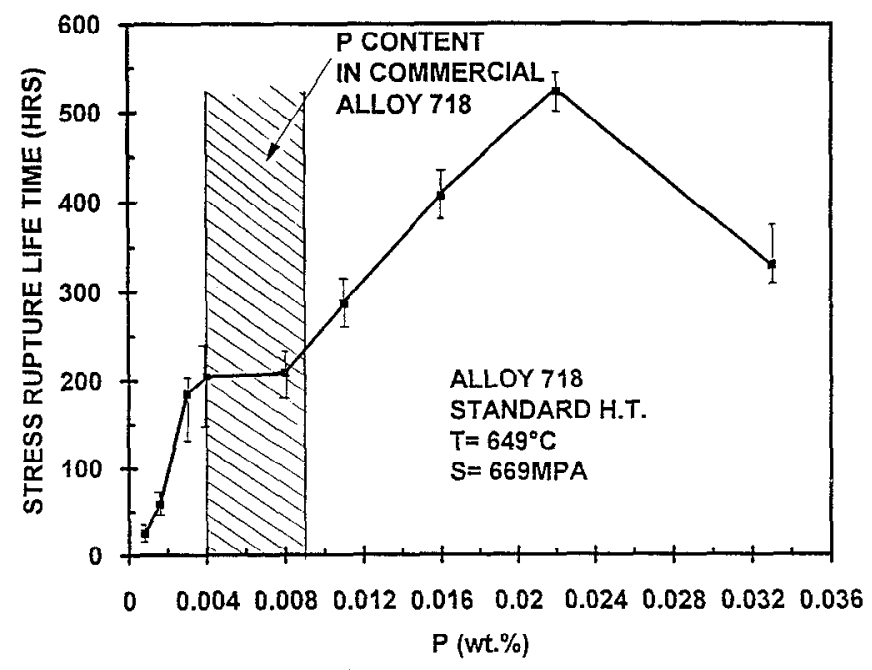

Fig. 6. Effect of $P$ Level on Stress Rupture Life Time of Alloy 718 , Standard Heat Treatment, S $=669 \mathrm{MPa}$.

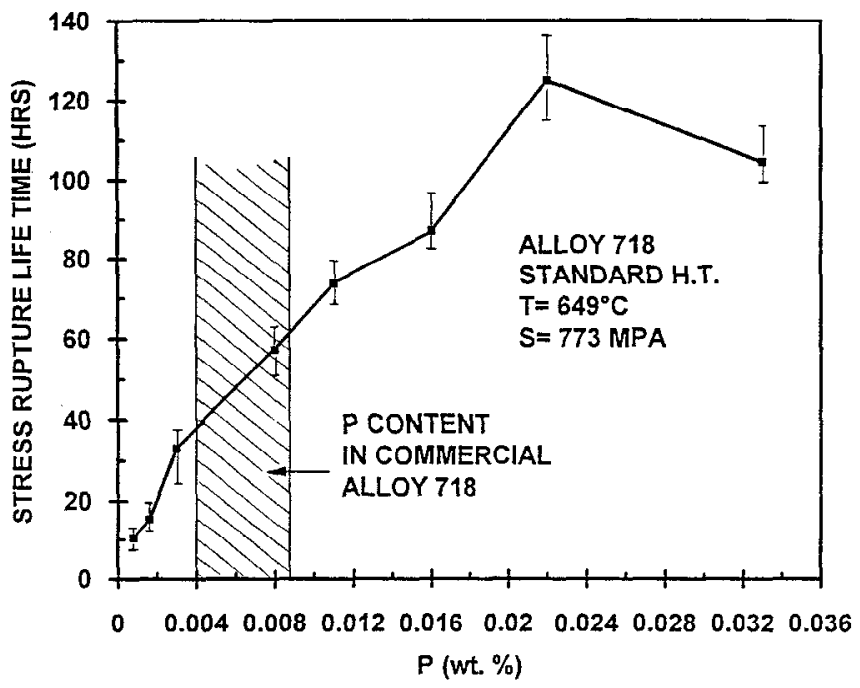

Fig. 7. Effect of $P$ Level on Stress Rupture Life Time of Alloy 718 , Standard Heat Treatment, S $=773 \mathrm{MPa}$. 

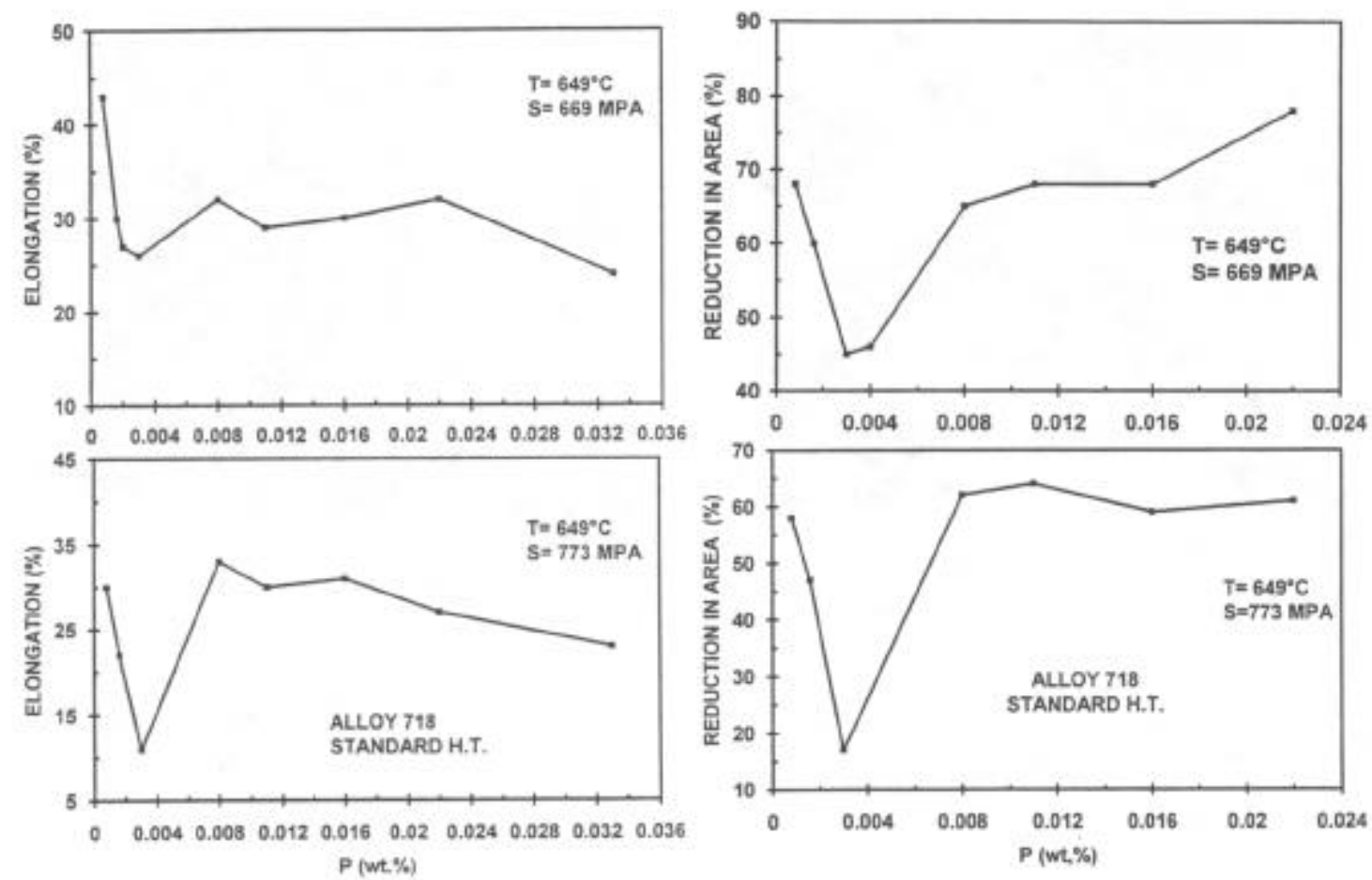

Fig. 8. Effect of $\mathbf{P}$ Content on Stress Rupture Elongation of Alloy 718, Standard Heat Treatment.

Fig. 9. Effect of $P$ Content on Stress Rupture Reduction in Area of Alloy 718 , Standard Heat Treatment.

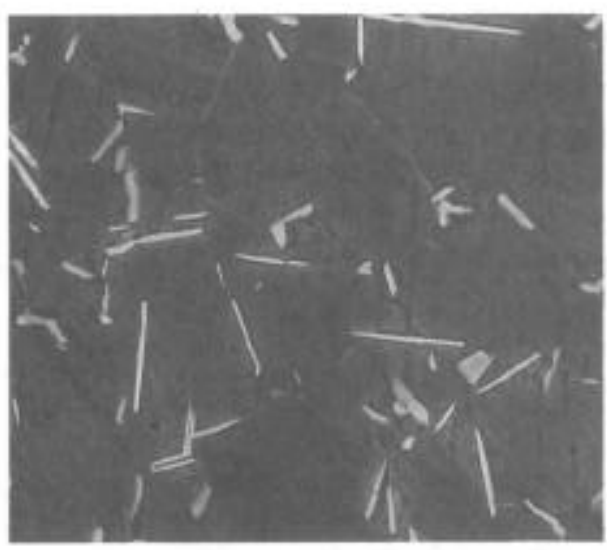

(a)

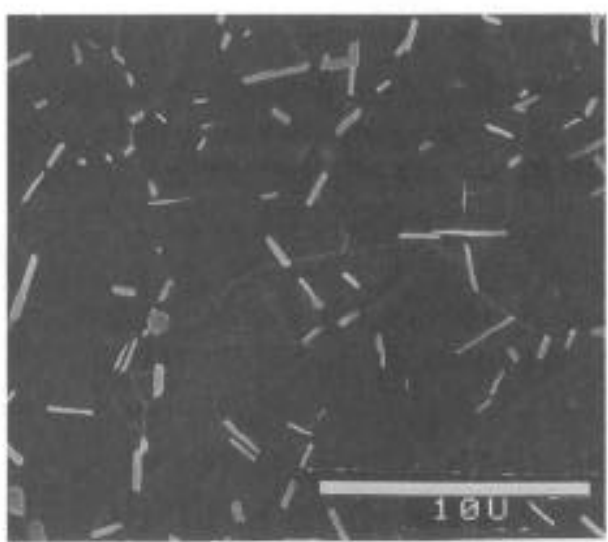

(b)

Fig. 10. SEM Photographs of the Microstructures of Test Alloys Before $(a, b)$ and After (c,d) Stress Rupture Test - (a) $0.006 \% \mathrm{P}$, (b) $0.022 \% \mathrm{P}$ (Con't). 


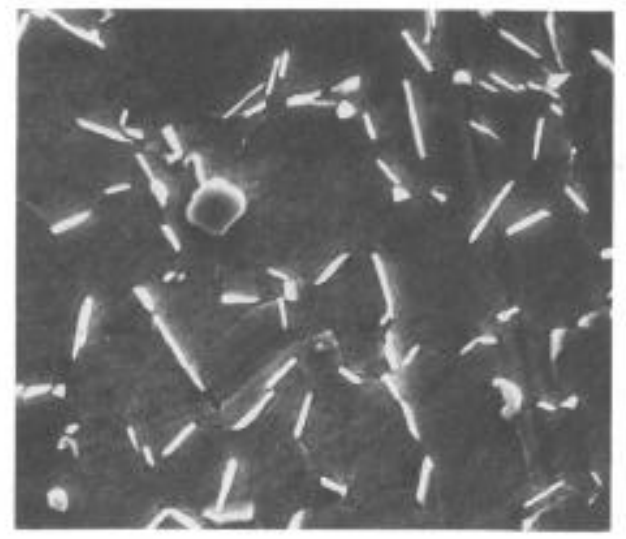

(c)

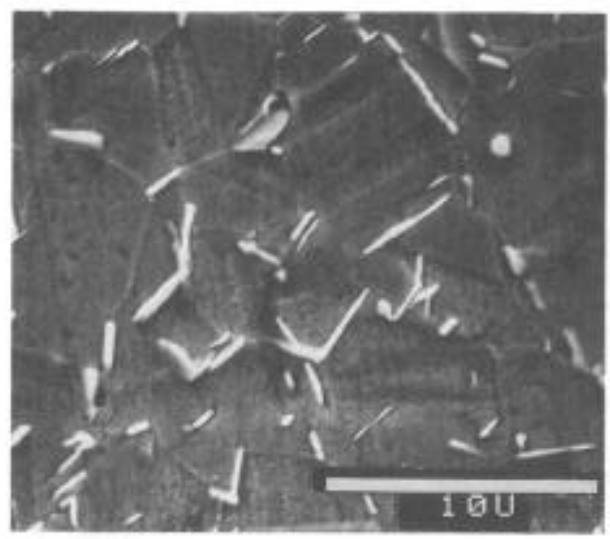

(d)

Fig. 10. (Cont'd) SEM Photographs of the Microstructures of Test Alloys Before $(a, b)$ and After (c,d) Stress Rupture Test - (c) $0.006 \%$ P, and (d) $0.022 \%$ P.
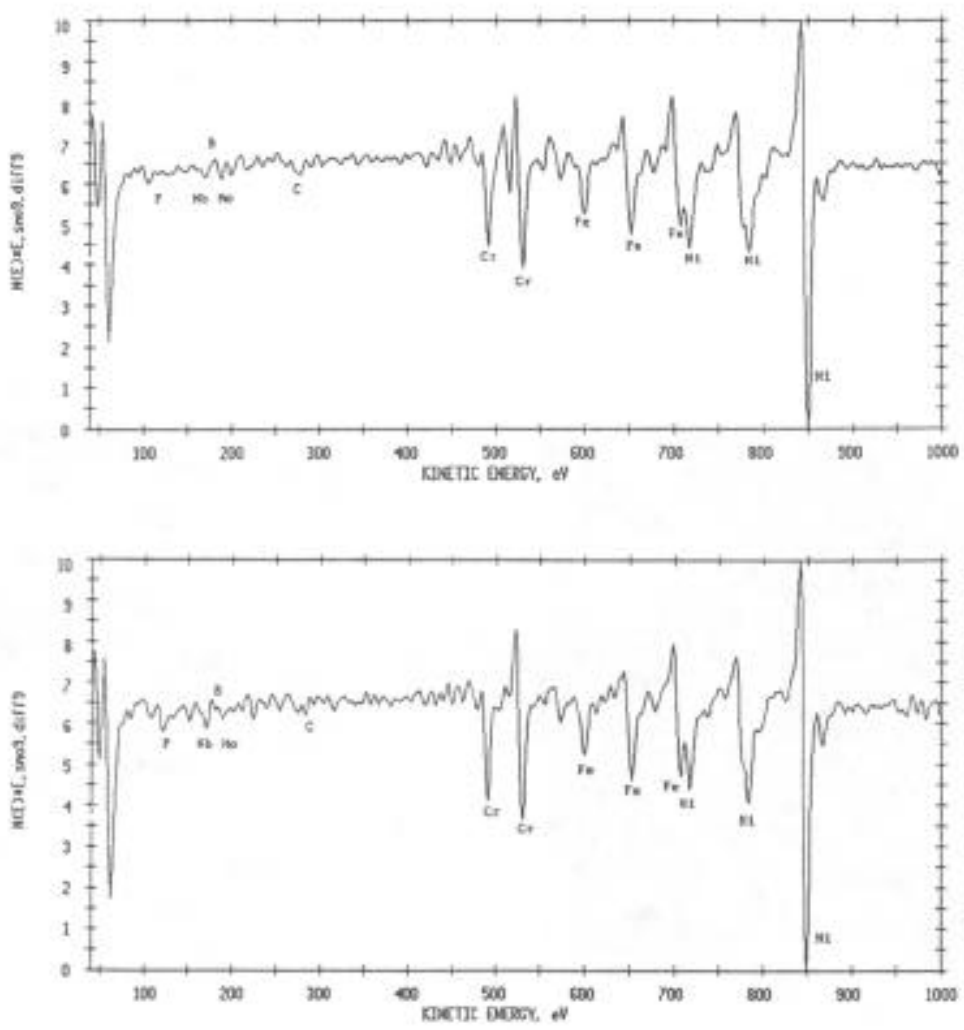

Fig. 11. AE Spectra of Test Alloys with: (a) $0.0007 \% \mathrm{P}$ and (b) $0.011 \% \mathrm{P}$. Note the Change in Height of $\mathrm{P}$ Peak with Increasing $\mathrm{P}$ With Other Peaks Being Almost the Same. 


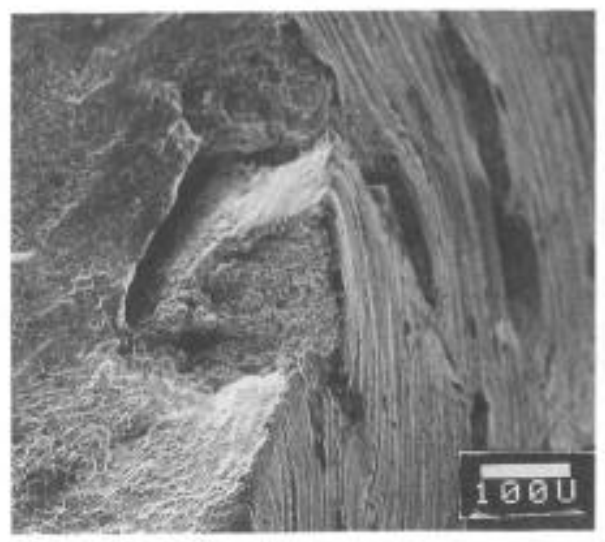

(a)

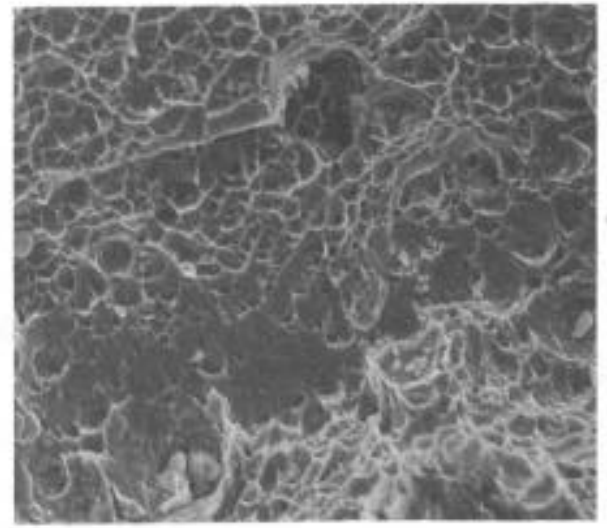

(c)

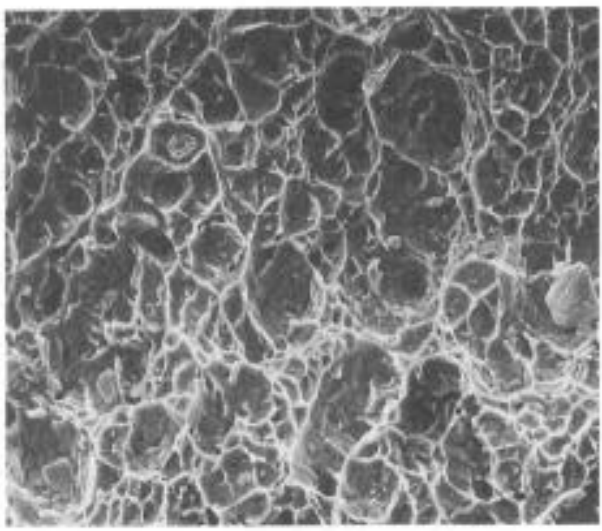

(e)

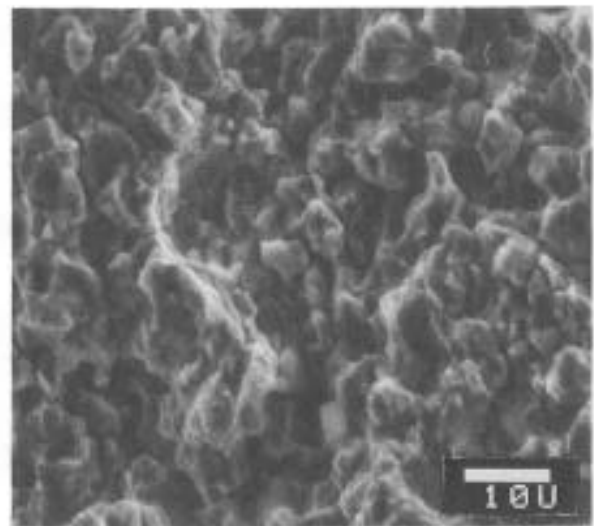

(b)

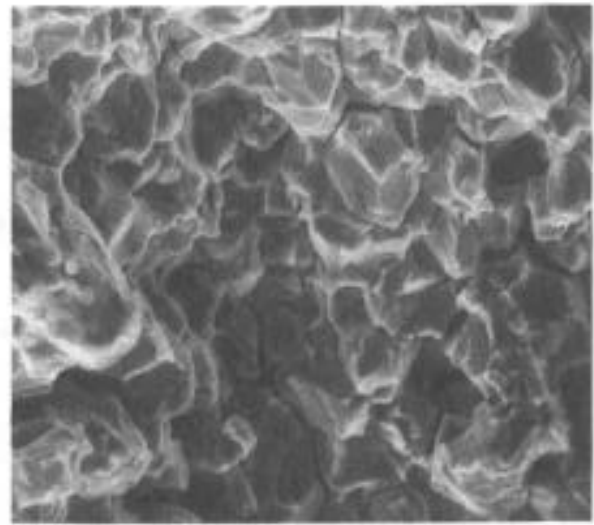

(d)

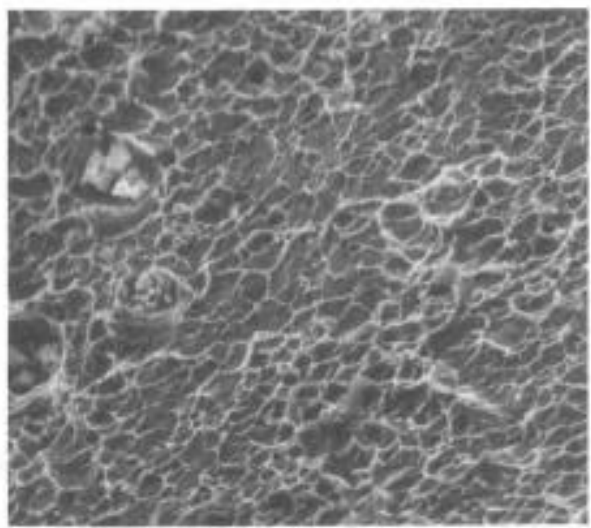

(f)

Fig. 12. SEM Fractographs of Broken Stress Rupture Specimens at Low Stress (669 $\mathrm{MPa})$, (a) Intergranular Cracking on Specimen Surface in Low P Alloy $(0.0007 \%$ P), (b) The Enlarged View of Intergranular Cracking. (c) Final Transgranular Fracture of Low P Alloy, (d) Intergranular Fracture in Alloy Containing $0.003 \%$ $\mathrm{P}$, (e) Transgranular Fracture in Alloy with $0.016 \% \mathrm{P}$, and $(\mathrm{f})$ Ductile Shear Fracture in Alloy with $0.022 \% \mathrm{P}$. 
mainly by transgranular dimple fracture, but the morphology of the dimpled surface was very different in high and low $P$ alloys. The fracture surface in low $P$ alloys was a duplex dimple structure consisting of large primary microvoids and fine secondary microvoids, (Fig. 13a). With increasing $P$ content, the fine secondary microvoid formation was suppressed so that a simple dimple structure consisting almost entirely of large primary voids was observed, (Fig. 13c). A similar phenomenon was also observed in the $649^{\circ} \mathrm{C}$ tensile and $816^{\circ} \mathrm{C}$ RSRTT. RSRTT fractures at all test temperatures greater than $816^{\circ} \mathrm{C}$ were intergranular.

\section{Discussion}

Based on the above results, the major effects of $P$ on mechanical properties of 718 can be summarized as follows:

(a) $\mathrm{P}$ contents above about $0.02 \% \mathrm{P}$ led to a slight reduction in the RSRT ductility of large grain size, as-cast 718 at high temperatures $\left(>927^{\circ} \mathrm{C}\right)$. The observed reduction in RSRTT ductility of an as-cast 718 probably resulted from the effect of $\mathrm{P}$ on microsegregation. $\mathrm{P}$ increases microsegregation, promotes Laves phase formation, and lowers the Laves/ $\gamma$ eutectic temperature $(14,15)$. In the worst case, segregated $P$, per se, may form a phosphide eutectic with a low melting temperature. After homogenization these effects were undoubtedly reduced but not totally eliminated so that reduced high temperature ductility was still observed. However, as shown by this study, $\mathrm{P}$ contents up to as high as $0.02 \%$ had no significant effect on high temperature ductility. While higher levels of $P$, between $0.02 \%$ and $0.03 \%$, did reduce RSRTT ductility, the effect was not sufficient to effect normal conversion results.

(b) $P$ increased the stress rupture life of fine grained 718 , most likely by reducing the creep strain rate and increasing the resistance to intergranular creep cracking. Figure 14 shows the average creep strain rate calculated from the life time and elongation as a function of $\mathrm{P}$ level. Even though this average strain rate does not distinguish the different creep stages and was not measured at constant stress, and, therefore, does not have a fundamental meaning, it can still serve as an indicator to show the effect of $P$ on the creep strain rate. An increase in the $P$ level from $0.0007 \%$ to $0.022 \%$ reduced the average creep strain rate by more than one order of magnitude. It is well established that a dislocation-creep mechanism dominates in alloy 718 at the temperature and stress levels applied in this study. The reduced creep strain rate must be the result of retardation of dislocation motion by $\mathrm{P}$ atoms in solution or precipitated phosphide particles. The detailed mechanism is not yet known and no phosphide particles have been identified, but similar phenomenon have been observed in IN600 $(9,10)$ and $20 \mathrm{Cr}-20 \mathrm{Ni}$ stainless steel (16).

(c) Increased $\mathrm{P}$ level enhanced the resistance to intergranular cracking of alloy 718 , as shown by the transition of fracture mode from intergranular to transgranular separation in stress rupture tests at lower stresses. This effect is probably related to increased $P$ segregation to grain boundaries which is the major change in grain boundary chemistry. It appears from this result that segregated $P$ actually increases rather than decreases the grain boundary cohesion in alloy 718 . This 


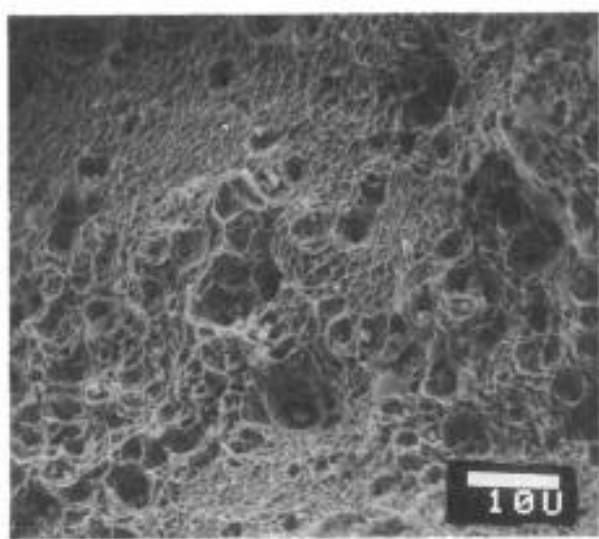

(a)

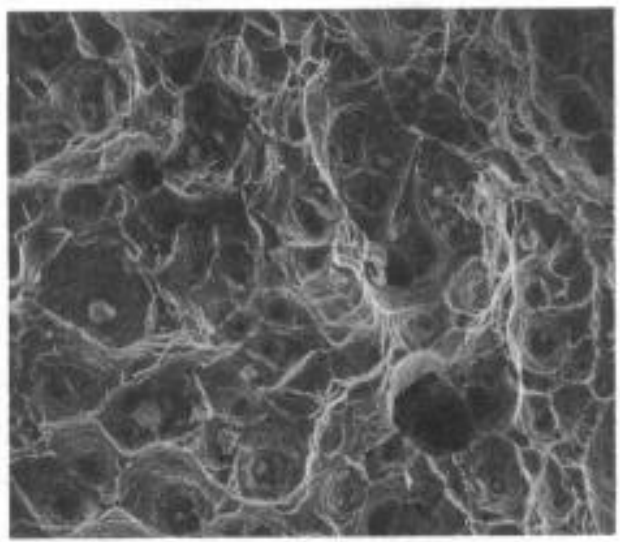

(c)

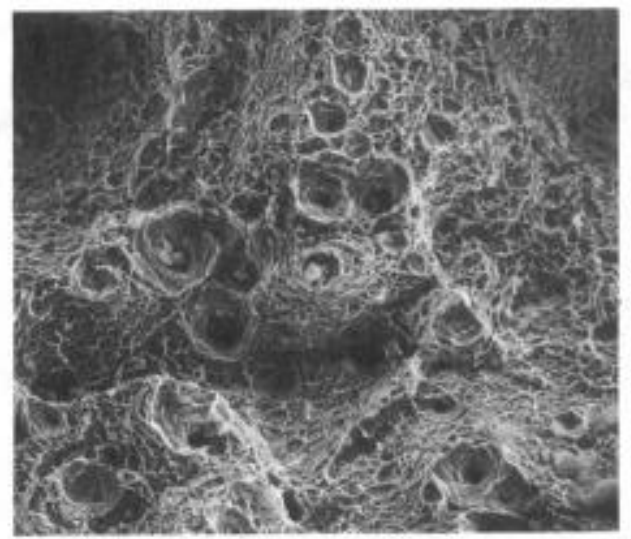

(b)

Fig. 13. SEM Fractographs of Broken Stress Rupture Specimens at High Stress (773 MPa), (a) Alloy with $0.0007 \% \mathrm{P}$, (b) Alloy with $0.016 \% \mathrm{P}$, (c) Alloy with $0.022 \% P$. Note the Change in Dimple Morphology, i.e. Decrease in Area Fraction of Fine Secondary Microvoids with Increasing P Content.

$P(w t . \%)$

$\begin{array}{llllllllllllllllllllllll}0 & 0.004 & 0.008 & 0.012 & 0.016 & 0.02 & 0.024 & 0.028 & 0.032 & 0.036\end{array}$

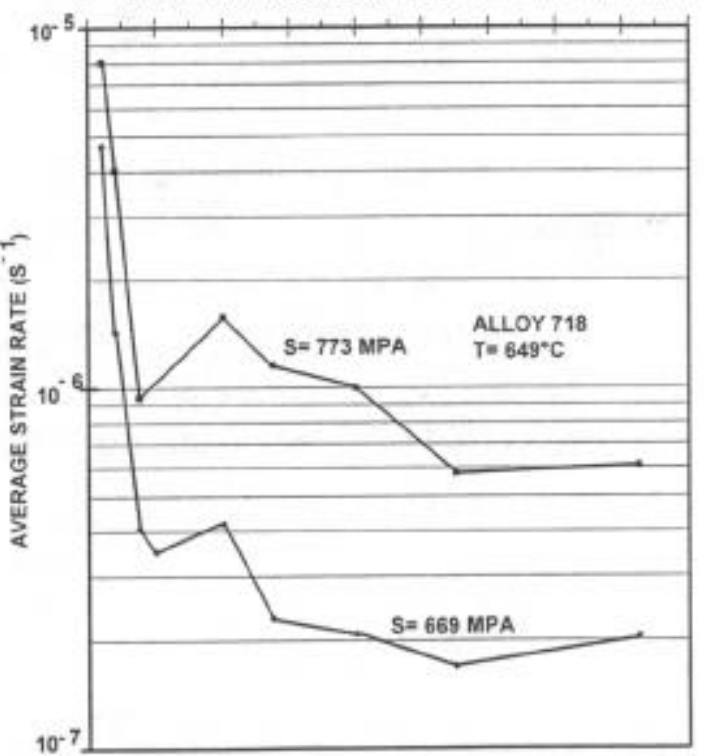


is in agreement with the observation made by Was and his co-workers (8-10) in $\mathrm{Ni}-\mathrm{Fe}-\mathrm{Cr}$ alloys. It is also not in conflict with the results in Ref. 6 and 7 which demonstrated the embrittlement effect of $P$ in nickel-base alloys, but only for ascast alloys at quite high temperatures, i.e. a phenomenon similar to effect (a) observed in this study. To the best of our knowledge, the effect of $P$ on grain boundary cohesion of alloy 718 has not been studied in any detail.

(d) A low phosphorous level $(\approx 0.003 \%)$ caused severe creep brittleness and, therefore, much lower stress rupture ductility. The reason for this is not yet clear.

The strong positive effect of $P$ on stress-rupture properties of fine grained alloy 718 may have important practical applications. Ultra-fine grained 718 , or mini-grain 718 , usually has superior high and low cycle fatigue properties but inferior stress rupture/ creep resistance. Increasing the $\mathrm{P}$ level may be helpful in resolving stress rupture/ creep limitation in fine grained 718 while maintaining equivalent strength, ductility, fatigue resistance, and processing characteristics. An extensive program is ongoing at Allvac to implement this concept in combination with optimizing other minor elements.

\section{$\underline{\text { Conclusions }}$}

1. The stress rupture life time of fine grained 718 was increased by $250 \%$ when the $P$ level was increased to $0.022 \%$ in comparison to conventional alloys containing $0.004 \%$ to $0.009 \% \mathrm{P}$. The increase in life time came from reduced creep strain rate, probably by impeding dislocation motion through P-dislocation interaction and reduction of intergranular cracking through increased grain boundary cohesion.

2. Increased $P$ up to around $0.02 \%$ slightly improved the ductility at elevated temperatures when the failure mode was transgranular microvoid fracture. It appears that $P$ suppressed the formation of fine secondary microvoids.

3. Increasing the $P$ level led to reduction in intergranular creep cracking, indicating that perhaps the segregation of $P$ to grain boundaries, as observed by AES study performed in this work, increases rather than decreases grain boundary cohesion.

4. Excess $P(>0.02 \%)$ in cast alloy 718 caused a reduction in ductility of RSRTT, particularly at higher temperatures. This effect may come from increased microsegregation.

5. Severe intergranular embrittlement was observed at very low levels of $P(\approx 0.003 \%)$ for which the mechanism is not yet known.

6. The positive effect of increased $P$ could be applied to improving stress rupture/ creep life in fine grain and mini-grain 718.

\section{References}

(1) C. G. Bieber and R. F. Decker, Trans. AlME, 221 (1961), 629-636.

(2) R. T. Holt and W. Walace, International Metals Reviews, 21 (1976), 1-24. 
(3) M. McLean and A. Strang, Metal Technology, 11 (1984), 454-464.

(4) G. W. Mectham, ibid, 11 (1984), 414-418.

(5) M. P. Seah, Acta Metall., 28 (1980), 955-962.

(6) W. Yeniscavich and C. W. Fox, "Effect of Minor Elements on the Weldability of High Nickel Alloys," Welding Research Council, (1969), 24-35.

(7) D. A. Cononico, W. F. Savage, W. J. Werner, and G. M. Goodman, ibid, 68-92.

(8) G. S. Was and R. M. Kruger, Acta Metall., 33 (1985), 841-854.

(9) J. K. Sung and G. S. Was, Corrosion, 47 (1991), 824-834.

(10) G. S. Was, J. K. Sung, and T. M. Angeliu, Met. Trans., 23 A (1992), 3343-3359.

(11) C. L. Briant, Met. Trans., 19A (1988), 137-143.

(12) R. G. Thompson, M. L. Koopman and B. H. King, "Superalloys 718, 625 and Various Derivatives," E. A. Loria, ed. (TMS 1991), 53-70.

(13) W. D. Cao, R. L. Kennedy, and A. Choudhury, Met. Trans., 24 A (1993), 18971907.

(14) Yao Xiao Zhu, Shunnan Zhang, Tian Xiang Zhang, Jinghua Zhang, Zhuangqi Hu, Xishua Xie, and Changxu Shi, Superalloys 1992, S. D. Antolovich et al., eds. (TMS, 1992), 145-154.

(15) W. D. Cao and R. L. Kennedy, "Effect of Minor Elements on Microsegregation in Alloy 718," (Paper presented at 123rd TMS Annual Meeting, San Francisco, 1994).

(16) P. R. Swann, Corrosion, 19 (1963), 102t-112t. 